\title{
IMMEDIATE PREOPERATIVE NUTRITIONAL STATUS OF PATIENTS WITH COLORECTAL CANCER: a warning
}

\author{
Luiza Regina L S BARBOSA ${ }^{1}$, Antonio LACERDA-FILHO ${ }^{2,3}$ and \\ Livia Cristina L S BARBOSA4
}

\begin{abstract}
Context - Weight loss and malnutrition are disorders observed in colorectal cancer patients. Objetives - We sought to evaluate the immediate preoperative nutritional status of patients with colorectal cancer. Methods - This is a cross-sectional clinical study conducted at a single center. Sixty-six consecutive patients in preoperative for elective surgical treatment were studied. The clinical history, socio-demographic data and nutritional status of the patients were evaluated using Subjective Global Assessment and objective (anthropometry) methods. The primary outcome measures were nutritional status classification as nourished or malnourished and the relationship between nutritional status and socio-demographic and clinical features. Results - Most of patients exhibited left colon tumors and disease stage II. According to the Subjective Global Assessment, 36.4\% of patients were malnourished. Malnutrition ranged from $7.6 \%$ to $53 \%$ depending on the evaluation method used, with poor correlation to Subjective Global Assessment. The prevalence of malnutrition was significantly greater in females and non-married patients and in those with two or more symptoms of colorectal cancer. Conclusion - More than a third of patients in the immediate preoperative period for colorectal cancer exhibited malnutrition. Therefore, routine nutritional assessment is highly advisable so that appropriate measures may be taken to minimize the potential postoperative complications.
\end{abstract}

HEADINGS - Colorectal neoplasms. Preoperative period. Malnutrition. Nutrition assessment.

\section{INTRODUCTION}

Cancer is the second leading cause of death worldwide and represents nearly $17 \%$ of deaths from known causes $^{(12,17)}$. Colorectal cancer (CRC) is the third most common type of cancer, accounting for approximately one million new cases per year worldwide ${ }^{(17)}$.

Due to the deep impact on physical, psychological and social functions caused by cancer, malnutrition commonly develops in these patients and is itself a risk factor for decreased immune response and postoperative complications, especially infectious, resulting in higher mortality ${ }^{(2,6,21,24)}$. It is assumed that, on average, $20 \%$ of cancer deaths are secondary to malnutrition ${ }^{(6,24)}$. Malnutrition further worsens the prognosis due to lower tolerance to neoadjuvant and or adjuvant therapy and leads to longer hospital stays, greater impairment of quality of life and increased medical costs ${ }^{(2,6,12,24)}$. Thus, early diagnosis of malnutrition is of increased importance among surgical patients, especially considering that many nutritional disorders can be corrected preoperatively in an attempt to decrease postsurgical morbidity and mortality $(6,19,24)$.

However, the nutritional status is frequently not adequately assessed by the medical staff, which negatively affects the response to treatment and increases the incidence of adverse effects ${ }^{(2,19)}$. Another difficulty in terms of nutritional assessment is the absence of an internationally accepted standard method for classifying nutritional status, as there is no single ideal method that includes all aspects of malnutrition ${ }^{(10,13)}$.

Although few data are available on the nutritional status of patients with CRC in the preoperative outpatient setting, the relationship between preoperative weight loss and the increased rate of postoperative morbidity in this type of neoplasm has previously been described ${ }^{(4)}$. Thus, the present study was designed to identify the preoperative nutritional status of CRC patients through the use of objective and subjective methods of nutritional assessment, aiming to establish their possible correlations with demographic and clinical data of patients.

\footnotetext{
Declared conflict of interest of all authors: none

This study was supported in part by a grant from the Coordination of Improvement of Higher Education Personnel, a foundation of the Brazilian Ministry of Education of Brazil (Capes/MEC).

Departamento de Nutrição, Hospital Felicio Rocho; ${ }^{2}$ Departamento de Cirurgia Colorretal, Hospital Felicio Rocho; ${ }^{3}$ Departamento de Cirurgia, Faculdade de Medicina, Universidade Federal de Minas Gerais; ${ }^{4}$ Universidade Vale do Rio Verde - UNINCOR. Belo Horizonte, MG, Brasil.

Correspondence: Antonio Lacerda-Filho. Departamento de Cirurgia. Faculdade de Medicina - UFMG. Av. Alfredo Balena 110, $2^{\circ}$ andar. CEP: $30130-100$. Belo Horizonte, MG, Brasil. E-mail: alacerda@ufmg.br
} 


\section{METHODS}

This is a cross-sectional clinical study that analyzed 66 patients with colorectal cancer recruited from a colorectal surgery outpatient unit, between July 2011 and December 2012, who were candidates for elective surgery. Patients younger than 18 years of age, those with previous clinical conditions potentially causing chronic malnutrition (presence of another cancer or other chronic wasting diseases) and those with mental deficits or other cognitive impairments that made it impossible to respond to a standard questionnaire, as well as those undergoing operations under urgent/emergency situations, were excluded from the study.

Patients were initially assessed for clinical data such as the time from onset of disease, related symptoms (anorectal bleeding, mucus discharge, abnormal bowel habits, stool narrowing and abdominal pain), tumor location (right colon up to the splenic flexure, left colon corresponding to the descending and sigmoid colon and rectum, including the recto sigmoid junction), preoperative stage disease (I, II, III and IV from the WHO/UICC classification) and presence of comorbidities. Patients were then referred to the nutritional evaluation and included in this study after signing the informed consent form. Socio-demographic variables (gender, age, marital status and level of education) were obtained, and the nutritional status evaluation was performed by the same certified nutrition specialist (LRLSB) as close as possible to the date of surgery, ranging from one to seven days beforehand.

Nutritional assessments investigated appetite, food intake (in kilocalories), recent changes in dietary patterns and complaints related to the gastrointestinal tract such as dysphagia, mucositis, odynophagia, dental prosthesis inadequacy and xerostomia. We further investigated physical activity habits, smoking and alcohol consumption. Subjective Global Assessment (SGA), considered our primary tool of nutritional assessment, classified the patient's nutritional status as nourished, suspected or moderately malnourished and severely malnourished ${ }^{(8)}$. Finally, anthropometry was performed, assessing weight, height, percentage of weight loss (PWL), body mass index (BMI), arm circumference (AC), triceps skinfold (TSF), arm muscle area (AMA) and mid-arm circumference (MAC).

This study was approved by the Research Ethics Committee of the Felicio Rocho Hospital (CEP229/07/HFR) and the Ethics Committee of the Federal University of Minas Gerais (COEP/UFMG 00540203000-10).

\section{Statistical analysis}

Data were analyzed using the statistical program SPSS version 15.0 (SPSS Inc., Chicago, IL, USA). Sample calculation with a confidence level of $95 \%$ was established according to the lower incidence of malnutrition in patients with colorectal cancer, obtained by Planas et al. ${ }^{(18)}$. For qualitative variables, frequency distributions and percentages were calculated, whereas for quantitative variables, the mean, the standard deviation, the median and the interquartile range were determined. The analysis of an association between variables considered the prevalence ratio, and when this value was less than $20 \%$, the linear logistic regression model of Poisson was used. The power of associations was calculated using univariate analysis using the Pearson chi-square, either asymptotic or exact. Subsequently, a multivariate Poisson regression was conducted with all variables that were significant at the 0.05 level and their adequacy was tested using means of deviance tests and the chi-square test. The model was considered adequate if the $P$ value was less than 0.05 . To analyze the relationship between the classifications of SGA and quantitative variables, we used the Student's t test or Mann-Whitney test. The normality of the sample was assessed using the Shapiro-Wilk test. The agreement between the objective and subjective methods of nutritional assessment was based on the kappa index Test. An index value between zero and 0.2 indicates a poor correlation, between 0.21 and 0.6 indicates a slight to moderate correlation, and between 0.61 and 1.0 indicates a good to strong correlation.

\section{RESULTS}

The mean age of patients was 61 years, and most patients were older than 65 years $(n=27,40.9 \%)$. There was a predominance of female $(\mathrm{n}=36,54.5 \%)$ and Caucasian $(\mathrm{n}=38,57.6 \%)$ patients. The majority of the sample were married $(n=41,62.1 \%)$. Most patients completed a middle school education $(n=29,43.9 \%)$ The demographic data are depicted in Table 1.

TABLE 1 . Social and demographic features of patients immediately prior to operation for colorectal cancer $(n=66)$

\begin{tabular}{lccc}
\hline Features & Categories & n & $\%$ \\
\hline \multirow{4}{*}{ Age } & $\leq 30$ & 1 & 1.5 \\
& $31-40$ & 5 & 7.6 \\
& $41-50$ & 12 & 18.2 \\
Gender & $51-65$ & 21 & 31.8 \\
& $\geq 66$ & 27 & 40.9 \\
& & & \\
\multirow{4}{*}{ Race } & Female & 36 & 54.5 \\
& Male & 30 & 45.5 \\
& & & \\
& Afrodescendant & 4 & 6.0 \\
Marital status & Caucasian & 38 & 57.6 \\
& Mixed race & 24 & 36.4 \\
& & & \\
& Married & 41 & 62.1 \\
& Single & 8 & 12.1 \\
& Widower & 11 & 16.7 \\
& Divorced & 6 & 9.1 \\
& & & \\
& Illiterate & 4 & 6.1 \\
& Middle school & 29 & 43.9 \\
& High school & 15 & 22.7 \\
& Higher education & 15 & 22.7 \\
& Postgraduate & 3 & 4.5 \\
\hline \multirow{4}{*}{ Education level } & & &
\end{tabular}


The duration of the symptoms lasted up to 6 months in 41 patients $(62 \%)$, and $13(19.7 \%)$ had more than a year of symptoms by the time of diagnosis. With respect to signs and symptoms, 38 patients $(57.6 \%)$ had up to two symptoms of CRC; the most common symptoms were change in bowel habits and abdominal pain. Tumors of the left colon were the most prevalent $(n=23,34.8 \%)$, followed by rectal tumors $(\mathrm{n}=22,33.3 \%)$. With respect to tumor stage, the majority exhibited stage II disease $(\mathrm{n}=27,40.9 \%)$. Most patients had mild or well-controlled systemic disease $(n=43,65.2 \%)$, such as hypertension, diabetes mellitus and chronic obstructive pulmonary disease. The clinical features of our sample are described in Table 2.

Malnutrition ranged from $7.6 \%$ according to the BMI up to $53 \%$ according to TSF, among the various methods used for nutritional evaluation. Using the chosen gold standard method (SGA), $36.4 \%$ of patients were classified as malnourished (Table 3).

Appetite was decreased in 23 patients $(34.8 \%)$, with $69.6 \%$ of those classified as malnourished by SGA $(P<0.001)$ exhibiting this condition. The mean food intake was also significantly lowered among malnourished individuals when compared with nourished patients assessed by SGA $(1,261.7$ \pm 369.7 versus $1,930.8 \pm 255.9$ kcals, respectively; $P<0.001$ ).

Approximately $39.4 \%$ of the patients presented with weight loss, and $18.2 \%$ presented with severe loss. Overweight and obesity were present in $14.3 \%$ and $33.3 \%$ of the patients,

TABLE 2. Clinical features of patients immediately prior to operation for colorectal cancer $(\mathrm{n}=66)$

\begin{tabular}{|c|c|c|c|}
\hline Feature & Categories & $\mathrm{n}$ & $\%$ \\
\hline \multirow{4}{*}{$\begin{array}{l}\text { Onset of disease } \\
\text { (months) }\end{array}$} & $0-3$ & 20 & 30.3 \\
\hline & $4-6$ & 21 & 31.8 \\
\hline & $7-12$ & 12 & 18.2 \\
\hline & $\geq 13$ & 13 & 19.7 \\
\hline \multirow{3}{*}{ Number of symptoms } & $0-2$ & 38 & 57.6 \\
\hline & $3-4$ & 27 & 40.9 \\
\hline & $\geq 5$ & 1 & 1.5 \\
\hline \multirow{4}{*}{ Location of the tumor } & Right colon & 17 & 25.8 \\
\hline & Left colon & 23 & 34.8 \\
\hline & Rectum & 22 & 33.3 \\
\hline & Synchronous tumors & 4 & 6.1 \\
\hline \multirow{4}{*}{ Stage } & I & 18 & 27.3 \\
\hline & II & 27 & 40.9 \\
\hline & III & 9 & 13.6 \\
\hline & IV & 12 & 18.2 \\
\hline \multirow{2}{*}{ Metastasis } & Yes & 12 & 18.2 \\
\hline & No & 54 & 81.8 \\
\hline \multirow{3}{*}{ Comorbidities } & None & 22 & 33.3 \\
\hline & $\begin{array}{l}\text { Mild systemic } \\
\text { disease }\end{array}$ & 43 & 65.2 \\
\hline & $\begin{array}{l}\text { Severe systemic } \\
\text { disease }\end{array}$ & 1 & 1.5 \\
\hline
\end{tabular}

respectively, but it is noteworthy that some of these patients were also diagnosed as malnourished, according to SGA (Table 4). There were differences between nourished and

TABLE 3. Nutritional features of patients immediately prior to operation for colorectal cancer assessed by Subjective Global Assessment (SGA) and objective methods (anthropometry) $(\mathrm{n}=66)$

\begin{tabular}{|c|c|c|c|}
\hline $\begin{array}{l}\text { Nutritional } \\
\text { assessment methods }\end{array}$ & Nutritional features & $\mathrm{n}$ & $\%$ \\
\hline \multirow{3}{*}{$\begin{array}{l}\text { Subjective Global } \\
\text { Assessment }\end{array}$} & Nourished & 42 & 63.6 \\
\hline & $\begin{array}{l}\text { Mild to moderate } \\
\text { malnutrition }\end{array}$ & 17 & 25.8 \\
\hline & Severe malnutrition & 7 & 10.6 \\
\hline \multirow{6}{*}{ Body mass index } & Severe malnutrition & 1 & 1.5 \\
\hline & Mild malnutrition & 4 & 6.1 \\
\hline & Eutrophic & 29 & 43.9 \\
\hline & Overweight & 28 & 42.4 \\
\hline & Class I obesity & 3 & 4.5 \\
\hline & Class II obesity & 1 & 1.5 \\
\hline \multirow{3}{*}{$\begin{array}{l}\text { Weight loss } \\
\text { (percentage of WL) }\end{array}$} & Significant loss & 14 & 21.2 \\
\hline & Severe Loss & 12 & 18.2 \\
\hline & No loss & 40 & 60.6 \\
\hline \multirow{6}{*}{ Arm circumference } & Severe malnutrition & 2 & 3.0 \\
\hline & Moderate malnutrition & 5 & 7.6 \\
\hline & Mild malnutrition & 11 & 16.7 \\
\hline & Eutrophic & 42 & 63.6 \\
\hline & Overweight & 5 & 7.6 \\
\hline & Obesity & 1 & 1.5 \\
\hline \multirow{6}{*}{ Triceps skinfold } & Severe malnutrition & 21 & 31.8 \\
\hline & Moderate malnutrition & 12 & 18.2 \\
\hline & Mild malnutrition & 2 & 3 \\
\hline & Eutrophic & 16 & 24.2 \\
\hline & Overweight & 3 & 4.5 \\
\hline & Obesity & 12 & 18.2 \\
\hline \multirow{3}{*}{ Arm muscle area } & Nourished & 54 & 81.8 \\
\hline & $\begin{array}{l}\text { Mild to moderate } \\
\text { malnutrition }\end{array}$ & 7 & 10.6 \\
\hline & Severe malnutrition & 5 & 7.6 \\
\hline \multirow{4}{*}{$\begin{array}{l}\text { Mid-arm } \\
\text { circumference }\end{array}$} & Severe malnutrition & 1 & 1.5 \\
\hline & Moderate malnutrition & 1 & 1.5 \\
\hline & Mild malnutrition & 9 & 13.6 \\
\hline & Eutrophic & 55 & 83.3 \\
\hline
\end{tabular}

TABLE 4. Subjective Global Assessment (SGA) and classification of overweight and obesity according to the body mass index (BMI) of patients in the preoperative period for colorectal cancer $(n=66)$

\begin{tabular}{lccc}
\hline \multirow{2}{*}{ BMI } & \multicolumn{2}{c}{ SGA } & \multirow{2}{*}{ Total } \\
\cline { 2 - 3 } & Nourished n (\%) & Malnourished n (\%) & \\
\hline Overweight & $24(85.7)$ & $4(14.3)$ & 28 \\
Class I obesity & $2(66.7)$ & $1(33.3)$ & 3 \\
Class II obesity & $1(100)$ & $0(0.00)$ & 1 \\
\hline
\end{tabular}


malnourished patients with respect to the following variables: measured weight, usual weight, percentage of weight loss, time of weight loss, height, BMI, AC and adequacy of AC, TSF, AMA and MAC (Table 5). There were no differences between nourished and malnourished patients with respect to complaints related to the gastrointestinal tract, physical activity, smoking and alcoholism.

Gender, marital status, time course of disease, number of symptoms, comorbidities, appetite and significance of weight loss were entered in the Poisson regression model, and after its adjustment, the final model included gender, marital status and the number of signs and symptoms, as depicted in Table 6. The prevalence of malnutrition in females was 3.02 times higher than in males, 1.99 times higher in unmarried patients and 1.80 times higher in patients with three or more symptoms.

Calculations of the agreement between SGA and objective methods of nutritional assessment (anthropometry) are described in Table 7. MAC did not agree with SGA. Arm circumference, AMA and BMI exhibited slight agreement, and TSF exhibited a tendency to agreement, which can be considered marginally concordant with the SGA.

\section{DISCUSSION}

Preoperative weight loss and malnutrition, in addition to the presence of malignancy, may increase the rates of postoperative morbidity and mortality $(3,4,10,11,13,19,21,25)$ and also negatively impact survival rates ${ }^{(3,24)}$. Therefore, early identification of malnutrition is important, as it allows for proper nutritional intervention, which is considered essential for improved better clinical outcomes ${ }^{(16)}$.

There is currently little information on the nutritional status of preoperative patients with colorectal malignancy ${ }^{(4)}$. However, this type of tumor does not tend to harm the nutritional status because it does not compromise the absorptive capacity ${ }^{(3,19)}$. Therefore, this study sought to contribute to the knowledge of the nutritional profile in the immediate preoperative period of patients with CRC using objective methods (anthropometry) and subjective assessment (Subjective Global Assessment).

The predominance of female patients $(54.5 \%)$ with a mean age of 61 years is consistent with the literature, in which the incidence of CRC increases with age and is most prevalent among patients between 50 and 70 years of age.

TABLE 5. Comparison between quantitative variables of the study and the Subjective Global Assessment (SGA) of patients immediately prior to operation for colorectal cancer $(n=66)$

\begin{tabular}{|c|c|c|c|}
\hline SGA & Malnourished* & Nourished* & $P$ \\
\hline Age & $61.25 \pm 15.70$ & $61.10 \pm 13,60$ & 0.967 \\
\hline Measured weight & $55.93 \pm 12.28$ & $71.14 \pm 11,46$ & $<0.0001$ \\
\hline Usual weight & $58.00 \pm 21.00$ & $69.40 \pm 12.25$ & 0.005 \\
\hline Percentage of weight loss & $10.24 \pm 10.76$ & $0.00 \pm 4.19$ & $<0.0001$ \\
\hline Time loss (months) & $6.00 \pm 8.25$ & $2.00 \pm 6.00$ & 0.009 \\
\hline Height $($ centimeters $=\mathrm{cm}$ ) & $1.59 \pm 0.093$ & $1.65 \pm 0.080$ & 0.006 \\
\hline Body mass index & $22.20 \pm 4.31$ & $26.14 \pm 3.37$ & $<0.0001$ \\
\hline Arm circumference $(\mathrm{cm})$ & $27.19 \pm 3.96$ & $31.33 \pm 2.85$ & $<0.0001$ \\
\hline Arm circumference Adequacy & $89.54 \pm 12.27$ & $100.23 \pm 8.54$ & 0.001 \\
\hline Triceps skinfold (TSF in cm) & $14.46 \pm 5.17$ & $16.43 \pm 6.27$ & 0.196 \\
\hline TSF adequacy & $63.19 \pm 44.49$ & $96.81 \pm 42.63$ & $<0.0001$ \\
\hline Arm muscle area (AMA in $\mathrm{cm}$ ) & $32.20 \pm 12.54$ & $47.29 \pm 12.51$ & $<0.0001$ \\
\hline Mid-arm circumference (MAC) & $22.65 \pm 3.19$ & $26.18 \pm 2.71$ & $<0.0001$ \\
\hline MAC adequacy & $98.45 \pm 11.63$ & $102.63 \pm 9.55$ & 0.119 \\
\hline
\end{tabular}

* Mean and standard deviation

TABLE 6. Results of multivariate regression analysis (Poisson model) between Subjective Global Assessment (SGA) and the qualitative variables of patients immediately prior to operation for colorectal cancer $(\mathrm{n}=66)$

\begin{tabular}{|c|c|c|c|c|c|c|}
\hline Feature & Categories & Malnourished n (\%) & Nourished n (\%) & RP & CI 95\% RP & $P$ \\
\hline Gender & $\begin{array}{l}\text { Female } \\
\text { Male }\end{array}$ & $\begin{array}{c}20(55.6) \\
4(13.3)\end{array}$ & $\begin{array}{l}16(44.4) \\
26(86.7)\end{array}$ & $\begin{array}{l}3.025 \\
1.00\end{array}$ & $\begin{array}{c}1.098 ; 8.329 \\
-\end{array}$ & $\begin{array}{c}0.032 \\
-\end{array}$ \\
\hline Marital status & $\begin{array}{c}\text { Married } \\
\text { Non-married }\end{array}$ & $\begin{array}{l}10(24.4) \\
14(56.0)\end{array}$ & $\begin{array}{l}31(75.6) \\
11(44.0)\end{array}$ & $\begin{array}{c}1.00 \\
1.998\end{array}$ & $1.082 ; 3.686$ & $0 . \overline{0} 27$ \\
\hline Symptoms of CRC & $\begin{array}{c}1 \text { or } 2 \\
3 \text { or more }\end{array}$ & $\begin{array}{l}11(28.9) \\
13(46.4)\end{array}$ & $\begin{array}{l}27(71.1) \\
15(53.6)\end{array}$ & $\begin{array}{c}1.00 \\
1.802 \\
\end{array}$ & $\frac{-}{1.038 ; 3.115}$ & 0.036 \\
\hline
\end{tabular}

CRC: colorectal cancer; RP: ratio of prevalence; CI 95\% RP: confidence interval of 95\% RP 
TABLE 7. Measuring agreement of objective methods of nutritional assessment (anthropometry) with the Subjective Global Assessment (SGA) of patients immediately prior to operation for colorectal cancer $(n=66)$

\begin{tabular}{|c|c|c|c|c|}
\hline \multirow{2}{*}{$\begin{array}{l}\text { Anthro- } \\
\text { pometry }\end{array}$} & \multirow{2}{*}{$\begin{array}{l}\text { Nutritional } \\
\text { status }\end{array}$} & \multicolumn{2}{|c|}{ SGA } & \multirow{2}{*}{ Kappa } \\
\hline & & Nourished & Malnourished & \\
\hline MAC & $\begin{array}{l}\text { Nourished } \\
\text { Malnourished }\end{array}$ & $\begin{array}{l}37(67.3) \\
5(45.5)\end{array}$ & $\begin{array}{c}18(32.7) \\
6(54.5)\end{array}$ & 0.148 \\
\hline AC & $\begin{array}{l}\text { Nourished } \\
\text { Malnourished }\end{array}$ & $\begin{array}{c}32(76.2) \\
5(27.8)\end{array}$ & $\begin{array}{l}10(23.8) \\
13(72.2)\end{array}$ & 0.449 \\
\hline TFS & $\begin{array}{l}\text { Nourished } \\
\text { Malnourished }\end{array}$ & $\begin{array}{l}12(75.0) \\
17(48.6)\end{array}$ & $\begin{array}{c}4(25.0) \\
18(51.4)\end{array}$ & 0.217 \\
\hline AMA & $\begin{array}{l}\text { Nourished } \\
\text { Malnourished }\end{array}$ & $\begin{array}{c}38(70.4) \\
4(33.3)\end{array}$ & $\begin{array}{c}16(29.6) \\
8(66.7)\end{array}$ & 0.267 \\
\hline BMI & $\begin{array}{l}\text { Nourished } \\
\text { Malnourished }\end{array}$ & $\begin{array}{c}42(68.9) \\
0(0.0)\end{array}$ & $\begin{array}{l}19(31.1) \\
5(100.0)\end{array}$ & 0.251 \\
\hline
\end{tabular}

SGA: Subjective Global Assessment; MAC: mid-arm circumference; TFS: Triceps Skinfold AMA: Arm Muscle Area; BMI: Body Mass Index.

Although the number of female patients was only slightly greater $(54.5 \%)$, this meets the estimate presented by the Brazilian National Cancer Institute (INCA) ${ }^{(12)}$, the highest prevalence of new cases of CRC in women. The prevalence of Caucasians patients $(57.6 \%)$ is similar to that reported in North America ${ }^{(20)}$. There was a predominance of married patients $(62.1 \%)$ and patients with a middle school education $(43.9 \%)$ in the sample. These findings likely reflect the socio-demographic profile of the Brazilian population.

With regard to disease presentation, the progression time was typically less than six months $(62.1 \%)$, with the majority of patients $(57.6 \%)$ exhibiting up to two symptoms and being classified with stage II disease $(40.9 \%)$. Because our population represented a sample of outpatient candidates to elective surgery, very locally advanced tumors causing acute complications such as bowel obstruction were not included. This may explain the predominance of tumors in early stages. However, the presence of metastatic disease was observed in almost $20 \%$ of patients at diagnosis, which is in agreement with the literature ${ }^{(9)}$.

We have found that $18.2 \%$ of patients exhibited severe preoperative weight loss, and this weight loss was present for a longer period of time among the malnourished. This is consistent with the observation of Burden et al., who reported that one in five patients with CRC presented with malnutrition in the preoperative period, from assessment of the percentage of weight loss ${ }^{(4)}$. This by itself emphasizes the importance of preoperative nutritional assessment in patients with CRC, as weight loss alone should always be used as a prognostic factor in relation to the surgical risk ${ }^{(13,22,23)}$.

However, malnutrition diagnosis is more than just weight loss and we have demonstrated that more than a third of patients $(36.4 \%)$ with CRC in the preoperative period were malnourished, as evaluated by the Subjective Global Assess- ment (SGA). The choice of SGA as the gold standard reflects its clinical feasibility without the necessity of any specific tool and according to the recommendations of the American and European Societies of Nutrition for routine practice ${ }^{(1,2,11)}$. Moreover, SGA has been indicated as a method of choice for surgical patients ${ }^{(8)}$, including those with $\mathrm{CRC}^{(4)}$. Nonetheless, we also used objective tools and compared them to the SGA.

The rate of malnutrition found in the present study ranged from $7.6 \%$ to $53 \%$ according to the method of nutritional assessment applied. The use of different methods of nutritional assessment in a cross-sectional study such as this implies the need for interpretation of the data in light of the limitations of each method ${ }^{(4)}$. For example, according to BMI, only $7.6 \%$ of patients had some type of malnutrition. However, many overweight and obese patients were diagnosed as being malnourished $(14.3 \%$ of overweight patients and $33.3 \%$ of patients with mild obesity) according to SGA. The latter is an essential clinical method covering several important symptoms and signs, which better reflects the overall dynamic situation of the patient. Meanwhile, the objective tools such as BMI, AC, MAC, and TSF assess body compartments, which are directly affected by age and body composition ${ }^{(13)}$. Thus, the findings related to objective assessment should be evaluated critically, as these measures change with age and, because most of the study population were elderly, decreased body composition of adipose tissue becomes more pronounced in patients of this age group ${ }^{(5)}$.

In the multivariate regression analysis including SGA and qualitative variables, we observed that the prevalence ratio of malnutrition was three times higher in females. The analysis of this fact may suggest that women with CRC are more prone to malnutrition. Although we cannot establish a cause-effect relationship because it is a cross-sectional study, this fact may be due to the physiology of female aging, as the decline of anthropometric variables with age is considerably higher in women than in men $^{(5)}$.

The prevalence of malnutrition was almost two-fold higher in patients who were unmarried. In an extensive review on marriage and health, Kiecolt-Glaser and Newton considered matrimony as the central relationship for most adults, and morbidity and mortality were certainly lower for married than for unmarried individuals in a variety of acute and chronic conditions, including cancer ${ }^{(14)}$. One can speculate that the lack of a steady partner can lead to indifference towards eating habits and the onset of signs of malnutrition. Furthermore, patients who live alone seek less healthcare in general ${ }^{(14)}$, and neglect the onset of symptoms, leading to delayed diagnosis and the consequent increase in poor nutritional status.

Another variable associated with the increased risk of malnutrition was the presence of three or more symptoms of CRC. This may be explained by the impairment of quality of life with the worsening of the disease and the consequent worsening of nutritional status ${ }^{(7,15)}$. However, we saw no association between the presence of metastatic disease and worse nutritional status, possibly due to the type of study.

The wide range of malnutrition rates among the different methods and the poor agreement with SGA may be 
related to individual variations inherent to each method of nutritional assessment. This is because objective methods evaluate specific parts and body composition, which does not necessarily provide nutritional diagnosis as $\mathrm{SGA}^{(8)}$. This is an important aspect when taking into consideration that the global population is becoming overweight and obese, thus pointing to the importance of relying on clinical (such as SGA) tools rather than on objective measures ${ }^{(4,8)}$.

\section{CONCLUSION}

The present study reinforces the need to perform a thorough assessment of nutritional status preoperatively, preferably as early as possible in patients with colorectal cancer. Therefore, the presence of a dietitian trained and qualified to do so in the interdisciplinary team becomes highly advisable in the preoperative evaluation of patients with CRC. This enables proper nutritional intervention, thus minimizing the risk of postoperative complications and a rise in hospital costs ${ }^{(18)}$. Further studies evaluating the postoperative outcomes of colorectal cancer patients in relation to preoperative nutritional status will be required to properly address this issue.

\section{ACKNOWLEDGMENTS}

The authors would like to thank all the medical staff of Department of Colorectal Surgery, Hospital Felicio Rocho, by supply the patients enrolled in this study. Our special thanks to Prof. Maria Isabel Toulson D. Correia for her criticism on the final revision of the manuscript.

Barbosa LRLS, Lacerda-Filho A, Barbosa LCLS. Estado nutricional de pacientes com câncer colorretal em pré-operatório imediato: um alerta. Arq Gastroenterol. 2014,51(4):331-36.

RESUMO - Contexto - A perda de peso e a desnutrição são alterações observadas em pacientes com cancer colorretal. Objetivos - Avaliar o estado nutricional pré-operatório de pacientes com cancer colorretal. Métodos - Trata-se de estudo clínico transversal conduzido em um único centro. Foram estudados 66 pacientes consecutivos em pré-operatório de cirurgia eletiva. Os dados clínicos, sócio-demográficos e o estado nutricional dos pacientes foram avaliados utilizando-se a Avaliação Subjetiva Global e métodos objetivos (antropométricos). Visou-se obter a classificação nutricional em nutridos ou malnutridos e a relação entre o estado nutricional e os dados clínicos e sócio-demográficos. Resultados - A maioria dos pacientes apresentava tumores localizados no cólon esquerdo e doença em estágio II. De acordo com a Avaliação Subjetiva Global, 36,4\% dos pacientes eram malnutridos. A desnutrição variou de 7,6\% a 53\%, dependendo do método de avaliação nutricional empregado, havendo baixa correlação entre eles e a Avaliação Subjetiva Global. A prevalência de desnutrição foi significativamente maior em pacientes do sexo feminino, em não casados e naqueles pacientes com dois ou mais sintomas ou sinais de cancer colorretal. Conclusão - Mais de 1/3 dos pacientes com cancer colorretal no período de pré-operatório imediato apresentam desnutrição. Desta forma, a avaliação rotineira do estado nutricional é altamente desejável, no sentido de que medidas sejam tomadas a fim de minimizar potenciais complicações pós-operatórias.

DESCRITORES - Neoplasias colorretais. Período pré-operatório. Desnutrição. Avaliação nutricional.

\section{REFERENCES}

1. Arends J, Bodoky G, Bozzetti F, Fearon K, Muscaritoli M, Selga G, et al. ESPEN Guidelines on Enteral Nutrition: non-surgical: non-surgical oncology. Clin Nutr. 2006;25:245-59.

2. ASPEN Board Direct, Clinical Guidelines Task Force. Guidelines for the use of parenteral and enteral nutrition in adults and pediatric patients. J Parenter Enteral Nutr. 2002;26:1-138SA

3. Brown SC, Abraham JS, Walsh S, Sykes PA. Risk factors and operative mortality in surgery for colorectal cancer. Ann R Coll Surg Engl. 1991;73:269-72.

4. Burden ST, Hill J, Shaffer JL, Todd C. Nutritional status of preoperative colorectal cancer patients. J Hum Nutr Diet. 2010;23:402-7.

5. Burr ML, Phillips KM. Anthropometric norms in the elderly. Br J Nutr 1984;51:165-9.

6. Capra S, Ferguson M, Ried K. Cancer: impact of nutrition intervention outcome - nutrition issues for patients. Nutrition 2001;17:73-80.

7. Correia MITD, Waitzberg DL. The impact of malnutrition on morbidity, mortality, length of hospital stay and costs evaluated through a multivariate analysis. Clin Nutr. 2003;22:235-9.

8. Detsky AS, Mclaughlin JR, Baker JP, et al. What is subjective global assessment of nutritional status? J Parent Enter Nutr. 1987;11:8-13.

9. Fong Y, Kemeny N, Paty P, et al. Treatment of colorectal cancer hepatic metastasis. Semin Surg Oncol. 1996;12:219-52.

10. Garth AK, Newsome CM, Simmance N, Crowe TC. Nutritional status, nutrition practices and post-operative complications in patients with gastrointestinal cancer. J Hum Nutr Diet. 2010;23:393-401.

11. Huhmann MB, August DA. Review of American Society for Parenteral and Enteral Nutrition (ASPEN) Clinical Guidelines for Nutrition Support in Cancer Patients: nutrition screening and assessment. Nutr Clin Pract. 2008;23:182-8.

12. INCA. Instituto Nacional do Câncer. Estimativa 2010: incidência de câncer no Brasil. [Internet]. Rio de Janeiro: INCA, 2010. Available from: http://www.inca. gov.br/estimativa.

13. Jeejeebhoy KN. Nutritional assessment. Gastroenterol Clin North Am. 1998;27:347-69.
14. Kiecolt-Glaser JK, Newton TL. Marriage and Health: His and Hers. Psychol Bull. 2001;127:472-503

15. Majumdar SR, Fletcher RH, Evans AT. How does colorectal cancer present? Symptoms, duration, and clues to location. Am J Gastroenterol. 1999;94:3039-45.

16. Ottery FD. Definition of standardized nutritional assessment and intervention pathways in oncology. Nutrition. 1996;12:S15-9.

17. Parkin DM, Muir CS, Whelan SL, et al. Cancer Incidence in Five continents, vol 6. No 120. Lyon, France: International Agency for Researche on Cancer Scientific Publications, 1992.

18. Planas M, Peñalva A, Burgos R, Puiggrós C, Pérez-Portabella C, Espín E, et al. Guidelines for colorectal cancer: effects on nutritional intervention. Clin Nutrition. 2007;26:691-7.

19. Schwegler I, von Holzen A, Gutzwiller JP, Schlumpf R, Mühlebach S, Stanga Z Nutritional risk is a clinical predictor of postoperative mortality and morbidity in surgery for colorectal cancer. Br J Surg. 2010;97:92-7.

20. Semrad J, Tancredi DG, Baldwin LM, Green P, Fenton JJ. Geographic variation of racial/ethnic disparities in colorectal cancer testing among medicare enrollees. Cancer. 2011;117:1755-63.

21. Shils M, Shike M, Ross AC, et al. Modern Nutrition in Health and Disease. 10th ed. New York: Lippincott Williams \& Wilkins, 2006.

22. Sungurtekin, H, SungurtekinU, Balci C, Zencir M, Erdem E. The influence of nutritional status on complications after major intraabdominal surgery. J Am Coll Nutr. 2004;23:227-232.

23. Torres Udos S, Almeida TE, Netinho JG. Increasing hospital admission rates and economic burden for colorectal cancer in Brazil, 1996-2008. Rev Panam Salud Publica. 2010;28:244-248.

24. Waitzberg DL, Caiaffa WT, Correia MITD. Hospital malnutrition: the Brazilian national survey (IBRANUTRI): a study of 4000 patients. Nutrition. 2001; 17:573-80.

25. Waitzberg DL, Correia MITD. Nutritional assessment in the hospitalized patient Curr Op Clin Nutr Metab Care. 2003;6:531-8. 